\title{
Morphometry and Principle Component Analysis (PCA) Of Red House Spider NesticodesRufipes of South Bangalore, Karnataka
}

\author{
$*^{* 1}$ Jalajakshi, S. and ${ }^{* 2}$ Vinutha, C. \\ ${ }^{I}$ Department of Genetics Vijaya College Basavanagudi Bangalore, India. \\ ${ }^{2}$ Department of Zoology Vijaya College Basavanagudi Bangalore, India. \\ *1jlj_jala@yahoo.co.in*2vinuthacyril@gmail.com
}

\begin{abstract}
Nesticodes rufipes (Lucas 1846) commonly called as red house spider was collected and stored in $70 \%$ alcohol. The morphometric measurements and sexual dimorphism of both male and females were carried out. The male pedipalp and female epigynum were removed, mounted and detailed structure wasdescribed. The principle component analysis (PCA) was performed for 16 variables and found that female spiderdifferedfrom male spider significantly in all variables. The first principle component accounts for $82 \%$ of total variance with first pair of legs length as its dominant term(weightage 0.52588299) and the $2^{\text {nd }}$ principle component whose dominant term is the total body breadth measured in dorsal view with a percentage total variance of 94\%(weightage 0.40512341). Since the first two components together account for $0.9384 \%$ of the total variance, each individual was represented as apoint in the co-ordinate space, of the associated amplitudes of the two principle components. The points fell as two obvious clusters confirming the succinct sexual dimorphic feature of the spiders.
\end{abstract}

Keywords:Nesticodes rufipes, Morphometric measurements, Pedipalp, Epigynum \& Principal Component Analysis(PCA)

\section{Introduction:}

Therididae(Sundevall1853) is alarge family of spiders,also known as the tangle web spiders,cob web spiders \&comb footed spiders. The diverse family includes 86 genera and 2227 species (Platnick 2006). From India around 18 genus and 52 species has been reported. (Silwal, etal, 2005: Platnick N.I.,2011:Sebastian\& Peter,2009) Theridiids vary in general appearance and often shows sexual dimorphism. Morphological descriptions and a key to genera of the family therididaehas been documented. (Levi\&Levi1962).Most of the theridiid spiders are cosmopolitian and pantropical in distribution.

Nesticodes rufipes is commonly known as red house spider because it builds a small, tangled web in dark corners inside houses or under rims of garden pots.

\section{Materials and Methods:}

Male and female Nesticodes rufipes were collected by hand collection method both from house as well as garden. The specimen were brought to laboratory and stored in $70 \%$ alcohol. They were identified,by referring Journal of Arachnology "Identification to Indian Spiders" Seven females and five malespidersmorphometric measurements were done through calibrations under stereozoom microscope(Labomed). All variables were measured in $\mathrm{mm}$. The specimens were photographed byusing digital camera Nikon coolpixs6300. Further the Principle Component Analysis (PCA) was appliedto compare the variables of both males and females.

Observation:

Nesticodes rufipes female

General:

Females are dark brown slightly mottled, globular abdomen red brown legs.

Dorsal View- Prosoma: $2.19 \mathrm{~mm}$ in length \& $1.75 \mathrm{~mm}$ in width.

Opisthosoma: $3.76 \mathrm{~mm}$ in length \& $3.52 \mathrm{~mm}$ in width

Total Body Length $5.99 \mathrm{~mm}$

Total Length of Leg 1- $13.00 \mathrm{~mm}$, Leg 2- $10.24 \mathrm{~mm}, \mathrm{Leg} 3-7.71 \mathrm{~mm} \&$ Leg4 - 10.80mm

Prosoma: Golden brown in colour,triangular having blunt apex anteriorly and broad posterirorly covered with small stiff bristles dorsally while ventrallyit is paler with scarty bristles. Three pairs of eyes arranged compactly with two small opaque median pair in the first row and two lateral slightly larger opaque and the central pair are transparent oval in shape.

Ventrally the four pairs of elongated legs arise laterally from the triangular prosoma. Chelicerae are slender globular brown in colour. Mandibles are stout measuring $1.62 \mathrm{~mm}$ in length. All the four pairs of legs have 
uniform stump shaped trochantercharacter of theridiids being called "comb footed spider" (Fig4a)covered with numerous stiff bristles. The first pair of legs were the longest measuring $13.00 \mathrm{~mm}$, the $2^{\text {nd }}$ pair measuring 10.24 $\mathrm{mm}, 3^{\text {rd }}$ pair measuring $7.71 \mathrm{~mm}, \& 4^{\text {th }}$ pair measuring in $10.80 \mathrm{~mm}$ in length.(Table 01$)$

Opisthosoma: Is attached bya small flexible pedicel. It is pale golden brown in colormeasuring $1.75 \mathrm{~mm}$ at its widest region \& 2.19 mmin length (Table02) Dorsally there are two slightblack patches separated by a central white zone. The entire abdomen dorsally is covered with small stiff bristles in large number compared to ventral side with scarty bristlestwo pairsof spinnerets are subultimate in position encircled with a black rings on the ventral side.(Fig4b)

Epigynum:Measures $0.54 \mathrm{~mm}$ in diameter (Table 07). It is dark red circular in shape located anteriorly in the mid ventral region flanked in between two yellow triangular scleritized plates. These plates bear thick,dense bristles(Fig4c). Below the scleritized plates there is a depression called atrium. Atrium bears circular opening leading in to the adnexae(Roberts 1983). The female epigynum consists of two main parts namely viz external epigyne and internal adnexae, which are bilaterally symmetrical. The adnexae includes small ducts arising from the circular openings leading in to the seminal receptaculae,from these the short fertilizing tubes lead inside the vagina. (Fig4d)

\begin{tabular}{|l|l|l|l|l|l|l|l|l|}
\hline \multicolumn{7}{|c|}{ Table 01: Nesticodes rufipes: Females Leg Morphometric Measurements in mm } \\
\hline Feature & Leg1 & Std & Leg2 & Std & Leg3 & Std & Leg4 & Std \\
\hline Coxa & 0.62 & \pm 0.25 & 0.67 & \pm 0.19 & 0.62 & \pm 0.26 & 0.72 & \pm 0.27 \\
\hline Trochanter & 0.42 & \pm 0.19 & 0.31 & \pm 0.05 & 0.30 & \pm 0.06 & 0.39 & \pm 0.11 \\
\hline Femur & 3.52 & \pm 1.36 & 2.97 & \pm 1.16 & 2.07 & \pm 0.94 & 3.15 & \pm 1.06 \\
\hline Patella & 0.85 & \pm 0.20 & 0.87 & \pm 0.40 & 0.62 & \pm 0.17 & 0.84 & \pm 0.37 \\
\hline Tibia & 2.97 & \pm 1.16 & 2.13 & \pm 0.79 & 1.41 & \pm 0.49 & 2.25 & \pm 0.81 \\
\hline Tarsus & 4.62 & \pm 1.65 & 3.29 & \pm 1.20 & 2.69 & \pm 0.97 & 3.45 & \pm 1.32 \\
\hline Total & 13.00 & \pm 4.81 & 10.24 & \pm 3.79 & 7.71 & \pm 2.89 & 10.80 & \pm 3.94 \\
\hline
\end{tabular}

Table 02: Nesticodes rufipes: Female Body Morphometric Measurements in mm

\begin{tabular}{|l|l|l|l|l|}
\hline Character & Dorsal view & Std & Ventral view & Std \\
\hline Prosoma Length(PL) & 2.19 & \pm 0.66 & 1.95 & \pm 0.63 \\
\hline Prosoma Breadth(PB) & 1.75 & \pm 0.49 & 1.13 & \pm 0.37 \\
\hline Opisthosoma Length(OL) & 3.76 & \pm 0.44 & 3.58 & \pm 0.4 \\
\hline Opisthosoma Breadth(OB) & 3.52 & \pm 0.43 & 3.46 & \pm 0.38 \\
\hline Total Body Length(TBL) & 5.99 & \pm 0.95 & 5.59 & \pm 0.78 \\
\hline Total Body Breadth(TBB) & 5.52 & \pm 0.46 & 4.62 & \pm 0.59 \\
\hline
\end{tabular}

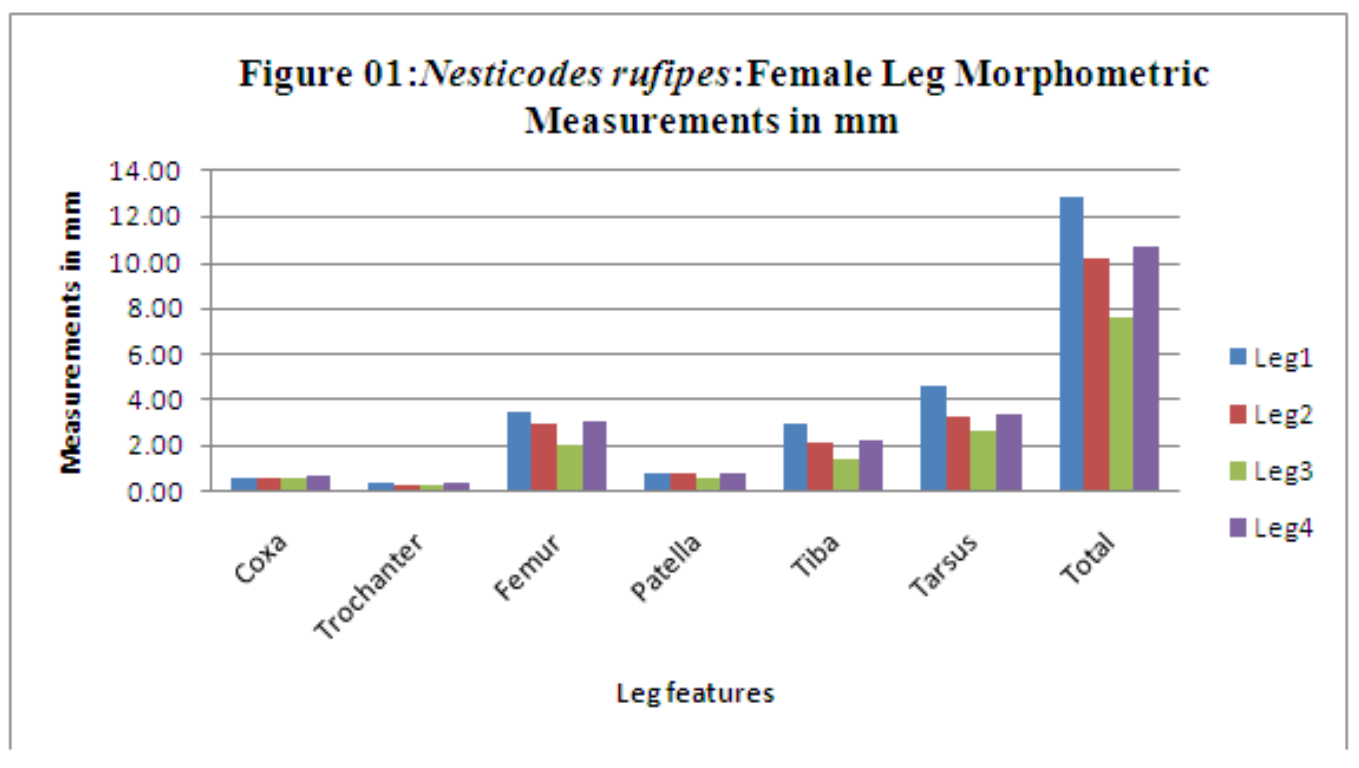




\section{Nesticodes rufipes male}

\section{General:}

Dorsal View- Prosoma: $1.46 \mathrm{~mm}$ in Length \& $1.22 \mathrm{~mm}$ in Width.

Opiosthosoma: $1.57 \mathrm{~mm}$ in Length \& $1.28 \mathrm{~mm}$ in Width

Total Body Length: $3.04 \mathrm{~mm}$

Total Length of: Leg 1- $9.49 \mathrm{~mm}$, Leg 2- $7.53 \mathrm{~mm}$, Leg 3- $5.15 \mathrm{~mm} \&$

Leg 4- $7.02 \mathrm{~mm}$

Prosoma: Pale golden yellow in colour,triangular in shape larger than opisthosoma measuring $3.04 \mathrm{~mm}$ in length and $1.28 \mathrm{mmin}$ width(Table-04)Prosoma has medially an elevated ridge with characteristic marking (Fig5a) with two stiff distinct bristles in the centre. Eye pattern is similar to that of female as described earlier.

Ventrally the sternum is smaller than dorsal carapace triangular in shape pale yellow in colour without any markings.(Fig5b). All the four pairs of legs have the unique stump shaped trochanter curved with numerous stiff bristles, the first pair being the longest of all the other pairsmeasuring $9.49 \mathrm{~mm}$ in total length, $2^{\text {nd }}$ pair measuring $7.53 \mathrm{~mm}, 3^{\text {rd }}$ pair measuring $5.15 \mathrm{~mm}, \& 4^{\text {th }}$ pair $7.02 \mathrm{~mm}$ (Table 04$)$

Opisthosoma: Is oval shaped smaller in size compared to prosoma measuring $1.74 \mathrm{~mm}$ in length and $1.41 \mathrm{~mm}$ in breadth (Table05). Dorsally two lateral patches appearing black, because of the dense stiff bristles. Ventrally opisthosoma has two lateral yellow patches flanking the horizontal genital slit. Posteriorly two pairs of spinnerets are found above and cup shaped surrounded by rings. The number of bristles are fewer compared to those found on the dorsal surface.(Fig05)

Pedipalp:The sexually mature male spider ofNesticodes rufipes has a complex second pair of appendages called pedipalpi. The pedipalp is of entelegyne type measuring $1.36 \mathrm{mmin}$ length and $0.97 \mathrm{~mm}$ in breadth(Table06). The coxa is broad articulating with the femur which hasa distinct femoral groove. The patella bears four prominent bristles at its apex. The tibia is very short forming the base of cymbium complex or embolus proper. The cymbium complex is elongated whip like structure turning clockwise in the left palp and in the right palp anticlockwise which is a character of all theridiids (Saaristo 1978). The paracymbium arises from the base of the cymbium ventrally which articulates bya movable joint. In between the cymbium and paracymbium internally has the alveolus forming two bulb like structures which continues as a coiled tube of receptaculamseminis. The terminal portion of the receptaculamseminis is the embolus. The entire structure is bulb like called the genital bulb. The bulb is divided in to three regions vizthe distal subtegulum, middle tegulum and terminal apophysis. The bulb also bears two prominent appendages the median apophysis and a hook like conductor or ejaculatory duct (Fig5c\&5d)

\begin{tabular}{|l|l|l|l|l|l|l|l|l|}
\hline \multicolumn{7}{|c|}{ Table 03: Nesticodes rufipes: Males Leg Morphometric Measurements in mm } \\
\hline Feature & Leg1 & Std & Leg2 & Std & Leg3 & Std & Leg4 & Std \\
\hline Coxa & 0.45 & \pm 0.09 & 0.41 & \pm 0.06 & 0.29 & \pm 0.05 & 0.39 & \pm 0.05 \\
\hline Trochanter & 0.34 & \pm 0.15 & 0.26 & \pm 0.04 & 0.21 & \pm 0.05 & 0.24 & \pm 0.10 \\
\hline Femur & 2.57 & \pm 0.39 & 2.28 & \pm 0.79 & 1.5 & \pm 0.26 & 1.94 & \pm 0.30 \\
\hline Patella & 0.58 & \pm 0.14 & 0.53 & \pm 0.17 & 0.39 & \pm 0.11 & 0.53 & \pm 0.10 \\
\hline Tiba & 2.36 & \pm 0.39 & 1.5 & \pm 0.35 & 1.05 & \pm 0.32 & 1.43 & \pm 0.27 \\
\hline Tarsus & 3.19 & \pm 0.60 & 2.55 & \pm 0.43 & 1.7 & \pm 0.52 & 2.5 & \pm 0.32 \\
\hline Total & 9.49 & \pm 1.26 & 7.53 & \pm 1.83 & 5.15 & \pm 1.32 & 7.02 & \pm 1.14 \\
\hline
\end{tabular}

\begin{tabular}{|l|l|l|l|l|}
\hline \multicolumn{2}{|c|}{ Table 04:Nesticodes rufipes: Male Body Morphometric Measurements } & \multicolumn{1}{c|}{ in mm } \\
\hline Character & Dorsal view & Std & Ventral view & Std \\
\hline Prosoma Length (PL) & 1.46 & \pm 0.26 & 1.1 & \pm 0.21 \\
\hline Prosoma Breadth(PB) & 1.22 & \pm 0.29 & 0.74 & \pm 0.12 \\
\hline Opisthosoma Length(OL) & 1.57 & \pm 0.11 & 1.74 & \pm 0.19 \\
\hline Opisthosoma Breadth(OB) & 1.28 & \pm 0.20 & 1.41 & \pm 0.40 \\
\hline Total Body Length(TBL) & 3.04 & \pm 0.29 & 2.83 & \pm 0.27 \\
\hline Total Body Breadth(TBB) & 2.50 & \pm 0.38 & 2.14 & \pm 0.36 \\
\hline
\end{tabular}




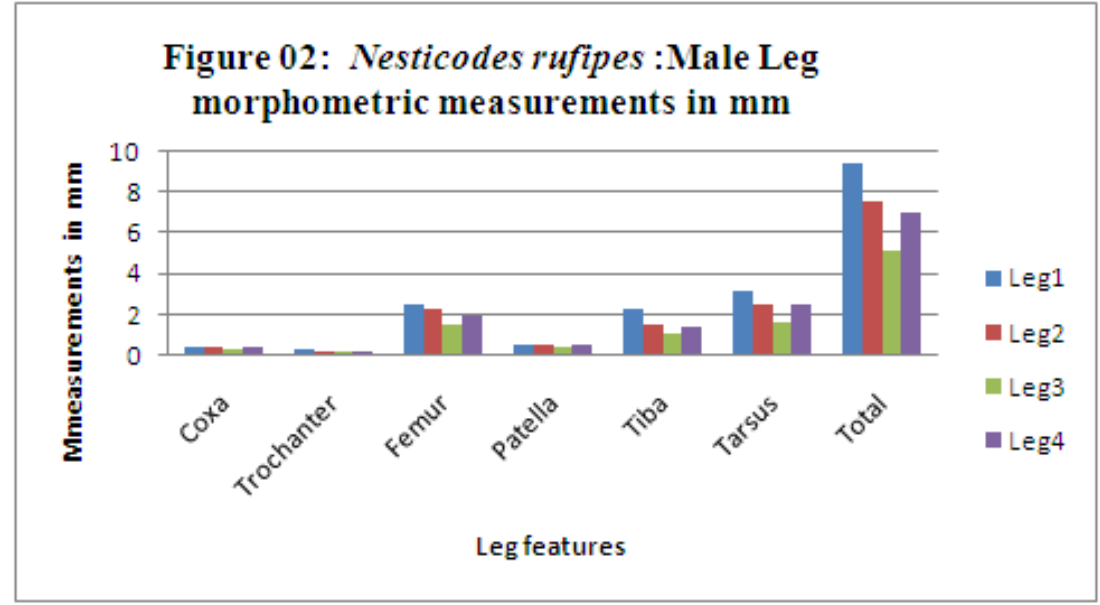

\begin{tabular}{|c|c|c|c|c|c|}
\hline \multicolumn{6}{|c|}{$\begin{array}{l}\text { Table 05:Nesticodes rufipes: Male and Female Morphometric } \\
\text { Measurements in mm }\end{array}$} \\
\hline Sl, no & Features & Male & & Female & Std \\
\hline 1 & Leg 1 & 9.49 & $=1.26$ & 13.00 & $=4.81$ \\
\hline 2 & Leg 2 & 7.53 & $=1.83$ & 10.24 & $=3.79$ \\
\hline 3 & Leg 3 & 5.15 & $=1.32$ & 7.71 & $=2.89$ \\
\hline 4 & Leșt & 7.02 & $=1.14$ & 10.80 & $=3.94$ \\
\hline 5 & P.L(D.V) & 1.46 & $=0.26$ & 2.19 & $=0.66$ \\
\hline 6 & $\mathrm{P} . \mathrm{B}(\mathrm{D}, \mathrm{V})$ & 1.22 & $=0.29$ & 1.75 & $=0.49$ \\
\hline & $\overline{0 . \mathrm{L}(\mathrm{D} . \mathrm{V})}$ & 1.57 & $=0.11$ & 3.76 & $=0.44$ \\
\hline 8 & $0 . B(D . V)$ & 1.28 & $=0.2$ & 3.52 & $=0.43$ \\
\hline 9 & P.L(V.V) & 1.10 & $=0.21$ & 1.95 & $=0.63$ \\
\hline 10 & $\overline{P . B(V . V)}$ & 0.74 & $=0.12$ & 1.13 & $=0.37$ \\
\hline 11 & $0 . \mathrm{L}(\mathrm{V} . \mathrm{V})$ & 1.74 & $=0.19$ & 3.58 & $=0.40$ \\
\hline 12 & $0 . B(V . V)$ & 1.41 & $=0.40$ & 3.46 & $=0.38$ \\
\hline 13 & T.B.L(D.V) & 3.04 & $=0.29$ & 5.99 & $=0.95$ \\
\hline 14 & $T . B . B(D . V)$ & 2.50 & $=0.38$ & 5.52 & $=0.46$ \\
\hline 15 & T.B.L(V.V) & 2.83 & $=0.27$ & 5.59 & $=0.78$ \\
\hline 16 & T.B.B(V.V) & 2.14 & $=0.36$ & 4.62 & $=0.59$ \\
\hline
\end{tabular}

\begin{tabular}{|c|c|c|}
\hline \multicolumn{3}{|c|}{$\begin{array}{l}\text { Table 06: Nesticodes rufipes: Morphometric measurements } \\
\text { of selected body parts of male and female in mm }\end{array}$} \\
\hline Body Feature & $\begin{array}{l}\text { Measurements } \\
\text { in mm }\end{array}$ & Std \\
\hline \multicolumn{3}{|l|}{ Female } \\
\hline Mandible Lenghth(M) & 1.62 & $=0.41$ \\
\hline Mandible Breadth (MB) & 1.12 & $=0.30$ \\
\hline Epigynum in diameter & 0.54 & $=0.17$ \\
\hline \multicolumn{3}{|l|}{ Male } \\
\hline Mandible Length(ML) & 0.94 & $=0.67$ \\
\hline Mandible Breadth(MB) & 1.47 & $=1.65$ \\
\hline Pedipalp Length(PL) & 1.36 & $=1.51$ \\
\hline Pedipalp Breadth(PB) & 0.97 & $=0.75$ \\
\hline
\end{tabular}

\begin{tabular}{|l|l|l|}
\hline \multicolumn{4}{|c|}{ Table 07: PCA for Different Body Features } \\
\hline & PC1 & PC2 \\
\hline LEG1 & -0.52588299 & -0.30785189 \\
\hline LEG2 & -0.42716671 & -0.30207069 \\
\hline LEG3 & -0.31922476 & -0.09038917 \\
\hline LEG4 & -0.47782815 & -0.12041582 \\
\hline PL(DV) & -0.08913371 & -0.01877479 \\
\hline PB(DV) & -0.05022253 & 0.01800687 \\
\hline OL(DV) & -0.13029073 & 0.29076603 \\
\hline OB(DV) & -0.11883614 & 0.32385558 \\
\hline PL(VV) & -0.08437915 & 0.03958760 \\
\hline PB(VV) & -0.04901022 & -0.01199780 \\
\hline OL(VV) & -0.09953772 & 0.27301851 \\
\hline OB(VV) & -0.11253585 & 0.29589837 \\
\hline TBL(DV) & -0.21953498 & 0.28060072 \\
\hline TBB(DV) & -0.16987099 & 0.40512341 \\
\hline TBL(VV) & -0.18413316 & 0.32945074 \\
\hline TBB(VV) & -0.16166624 & 0.29325870 \\
\hline Summary of PCA for pca1 \& pea2 & \multicolumn{2}{|l|}{} \\
\hline Standard deviation: & 6.8745 \\
\hline Proportion of \\
Variance in\%
\end{tabular}




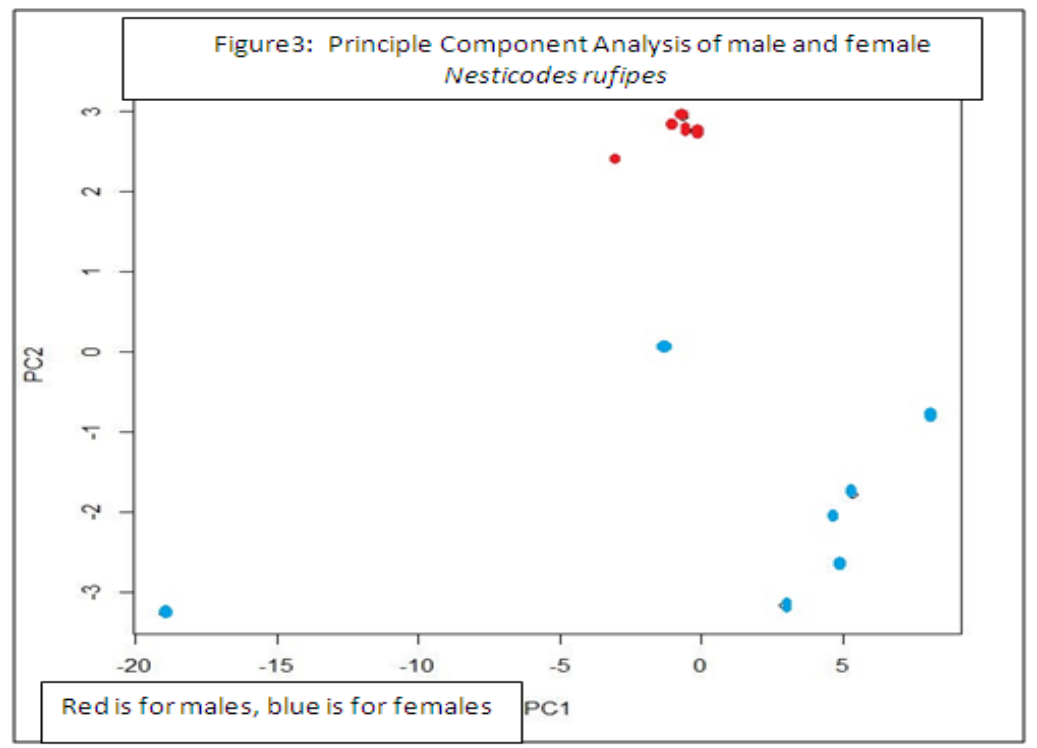

\section{Result and Discussion:}

Therididaeisamongst the largest family of the order Aranidae including 2.297 species subdivided in to 112 genera (Platnick 2010). The present study on the morphology of Nesticodes rufipes is very similar to that described by Saaristo(1978) of Seychelles Finland. However the morphometric analysis of male and female spider differed both in size \& body colouration, which might be due to geographical variations. The structure of both pedipalp of males and epigynum of female spiders were more complex in Indian spiders compared to that described by Finland species. (Fig $5 c \& d \& 4 c \& d$ respectively)

There is marked sexual dimorphism visibly seen between the male and female Nesticodes rufipes(Table 05\& 06). The females differed from males significantly in all the 16 variables studied. The principle component analysis performed with the data on body measurements of seven females and five males are presented in table 03 . The first principle component accounts for $82 \%$ of total variance with first pair of legs length as its dominant term (weightage 0.52588299 ) and the $2^{\text {nd }}$ principle component whose dominant term is the total body breadth measured in dorsal view with a percentage total variance of $94 \%$ (weightage 0.40512341 )(Table 07). Since the first two components together account for $0.9384 \%$ of the total variance, each individual is represented as a point in the co-ordinate space, of the associated amplitudes of the two principle components. The points felled as two obvious clusters confirming the succinct sexual dimorphic feature of the spiders.(fig:3)

\section{Acknowledgement:}

Thanks for University Grants Commission (UGC) Delhi for funding the project. We are alsothankfull for Mr.Milindcomputer analystIISC, Bangalore for guiding us in using PCA software, and all for his guidance.I personally thank my husband Mr. Srinivasa P.V, Technical Lead emidsBangalore, who helped in executing the PCA and plotting graph.

\section{References:}

[1]. Coddington, J. A. 1990. Ontogeny and homology in the male palpus of orb-weaving spiders and their relatives, with comments on phylogeny (Araneoclada: Araneoidea, Deinopoidea). Smithsonian Con-trib. Zool., 496:1-52

[2]. Levi, H. W.1962a. The spider genera Steatoda and Enoplognatha in America (Araneae, Theridiidae) Psyche 69(1):11-36

[3]. Levi, H. W. 1962b. More American spiders of the genus Chrysso (Araneae, Theridiidae) . Psyche 69(4) : 209-237

[4]. Lucas, H. 1846. Histoire naturelle des animauxarticules. In Exploration scientifique

[5]. del'Algerie . Paris, Sciences physiques, Zoologie, 1: 89-271

[6]. Platnick, N. I.2011. The World spider catalog, version 11.5. American Museum of Natural History.Available from: http://research.amnh.org/entomology/spiders/catalog/index.html. (accessed on 3rd February, 2011).

[7]. Roberts, M. J. 1983. Spiders of the families Theridiidae, Tetragnathidae and Araneidae (Arachnida: Araneae) from Aldabra Atoll. Zoological Journal of the Linnean Society $77 \quad 217-291$.

[8]. Saaristo, M.I. 1978. Spiders (Arachnida, Araneae) from the Seychelle Islands, with notes on taxonomy. Ann. Zool. Fennici 15: 99 126.

[9]. Sebastian, P.A., Peter, K.V.,2009. Spiders of India, First edition, Universities Press, Hyderabad

[10]. Wunderlich, J. 2008. On extant and fossil (Eocene) European comb-footed spiders (Araneae: Theridiidae), with notes on their subfamilies, and with descriptions of new taxa. BeitrageZurAraneologie 5, 140-469 
Figure 04: Nesticodesrufipes female

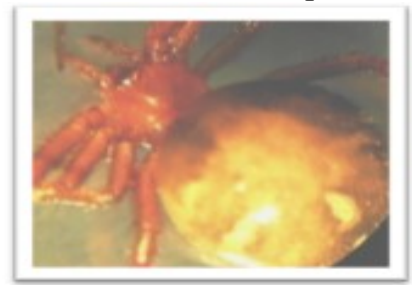

Figure 4a: Dorsal View
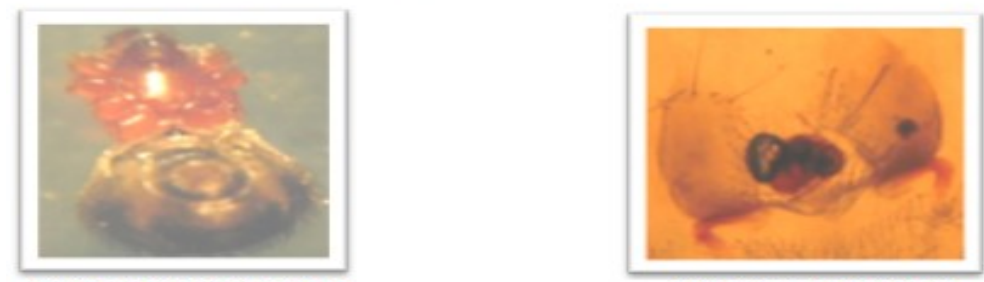

Figure 4 b: Ventral view

Figure4c: Epigynum

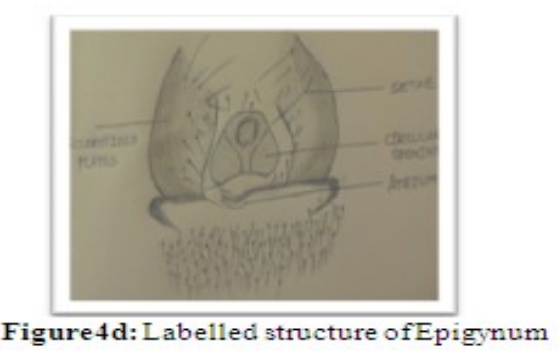

Figure 5: Nesticodes rufipes male
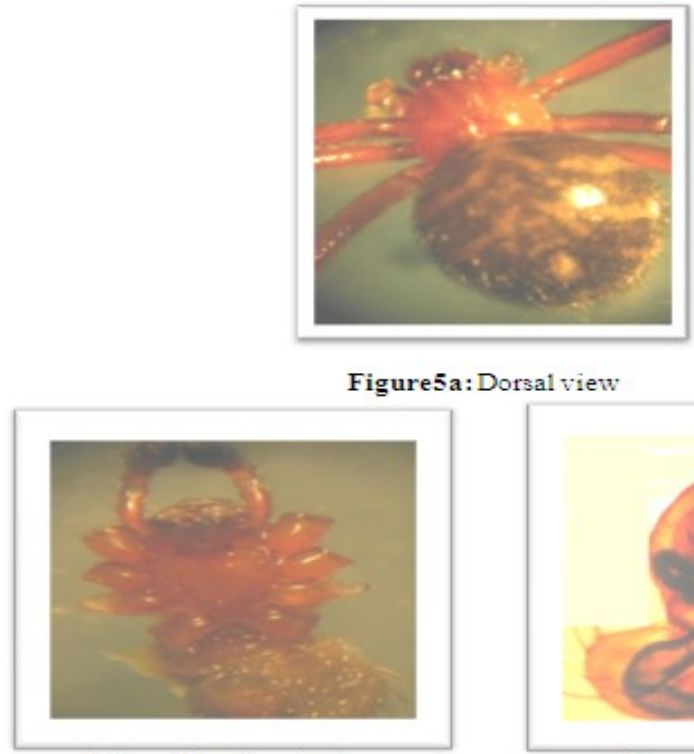

Figure5b: Ventral view

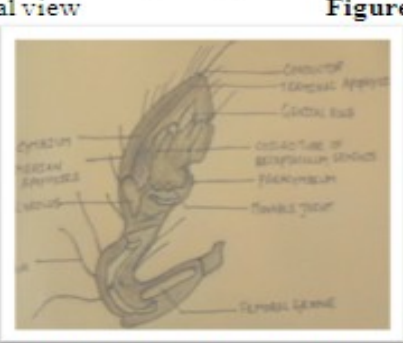

Figure5d: Labelled structure of Pedipalp 